\title{
Diversity and antibacterial activity of endophytic fungi associated with a hydrophyte Aponogeton natans
}

W. Jamith Basha ${ }^{1}$, Kalyanaraman Rajagopal ${ }^{2}$, B. Meenashree ${ }^{3}$, R. Arulmathi ${ }^{4}$, A.K. Kathiresan ${ }^{5}$, G. Gayathri ${ }^{5}$, G. Kathiravan ${ }^{2}$ and S.S. Meenambiga ${ }^{6} *$

${ }^{1}$ Department of Microbiology, Northern Border University, Arar, Kingdom of Saudi Arabia-91431.

${ }^{2}$ Department of Botany, Ramakrishna Mission Vivekananda College (Autonomous), Chennai- 600004, India.

${ }^{3}$ Asthagiri Herbal Research Foundation, Chennai- 600096

${ }^{4}$ Department of Biotechnology, School of Life Sciences, Vels Institute of Science Technology and Advanced Studies (VISTAS), Chennai- 600117, India.

${ }^{5}$ Department of Microbiology, School of Life Sciences, Vels Institute of Science Technology and Advanced Studies (VISTAS), Chennai- 600117, India

${ }^{6} *$ Department of Bio-Engineering, School of Engineering, Vels Institute of Science, Technology and Advanced Studies (VISTAS), Chennai, India.

*Corresponding Author Email: meenambiga.se@velsuniv.ac.in

(Submitted on August 10, 2019; Accepted on November 12, 2019)

\section{ABSTRACT}

\begin{abstract}
An endophytic fungus is an integral part the plant micro biome and colonizes the plant both systemically and non-systemically. In the present investigation endophytic fungi were isolated from leaf of a medicinally important hydrophyte, Aponogeton natans. Three hundred and fifty one isolates belonging to 15 different species were isolated.Alternaria alternata, Cytospora sp., Aspergillus fumigatus, Chaetomium incomptum and Phomopsis sp. showed higher colonization frequency. Alkaloids and Flavonoids were produced by all endophytic fungi in their crude extract and terpenoid was produced by 14 endophytic fungi. The antibacterial activity of ethyl acetate and diethylether extracts of four dominant endophytic fungi, viz. Alternaria alternata, Chaetomium incomptum, Phomopsis sp. and Sterile form I were tested. Bioactive compounds produced in ethyl acetate extract was more effective than diethylether compounds in inhibiting pathogens. Thus, this study provides an insight on the diversity of endophytic fungi and their varied anti-bacterial properties.
\end{abstract}

KEYWORDS: Hydrophyte, leaf, alkaloid, flavonoid, gram positive bacteria, gram negative bacteria

\section{INTRODUCTION}

Aponogeton natans is an aquatic and medicinally very important plant belonging to the family Aponogetonaceae. This plant parts as well as their extracts were used to treat anti diabetic, anaemia and haemothermia. It grows in seasonal, permanently still or free flowing waters, rice fields and marshy places. It is an important ornamental plant for aquariums and its tubers are fit for human consumption (Jamith Basha, 2016). Endophytic fungi reside in different parts of the plants like leaf, stem, bark, flower, etc. (Suryanarayanan, 2017). They are highly localized and are transmitted horizontally. As of now, endophytes have been isolated from all groups of plants ranging from sea grasses (Alva., 2002), lichens (Li et al., 2007), palms (Taylor et al., 1999; Frohlich et al., 2000), herbs, shrubs andlarge trees, etc. (Gonthier et al., 2006; Oses et al., 2008; Rajagopal, 1999). Endophytic fungi from tropical aquatic and wetland habitats were limited when compared to those growing on terrestrial moist or dry habitats, native hydrophytes and fresh water marshes (Kumar et al., 2014; You et al., 2016) Most endophytes isolated belongs to Ascomycetes and their anamorphs, Hyphomycetes, Coelomocytes and Basidiomycetes (Rungjindamai et al., 2008). Endophytic fungi residing in plants serve as important sources of new and novel metabolites which are bioactive (Vellingiri Manon Mani et al., 2015). Endophytes in general and endophytic fungi in particular from hydrophytes are poorly investigated even though they are important plant populations in a community. Hence, the aim of the present investigation was isolation and identification of endophytes from Aponogeton natans leaf and testing the selected endophytic fungal extracts for antibacterial activity.

\section{MATERIALS AND METHODS}

Isolation and Identification endophytic fungi:Ten to fifteen slender twigs of Aponogeton natans were collected from pond near Chennai city, Tamilnadu from April to June. Undamaged and healthy 5 to 10 leaves were collected from each twig. The leaves were collected in zip cover (sterile polythene bags) and processed within 24 hours of collection in the laboratory. The leaf segments of $0.5 \times 0.5 \mathrm{~cm}^{2}$ were cut from the plant samples using sterile scalpel (Cabral et al., 1993). These were then surface sterilized in $70 \%$ ethanol for 5 sec., immersed in $4 \%$ sodium hypochlorite $(\mathrm{NaOCl})$ for 10 sec. and rinsed in autoclaved double distilled water (Dobranic et al., 1995). The leaf segments were placed on Potato Dextrose Agar (PDA) medium amended with chloramphenicol $(100 \mathrm{mg} / \mathrm{L})$. The inoculated Petri plates were incubated at $27 \pm 1^{\circ} \mathrm{C}$ in light chamber for 2- 4 weeks for the growth of endophytic fungi. The light regime was kept at 12 hours followed by 12 hours darkness (Bills and Polishook, 1992). The endophytic fungal hyphae, which grew out from the leaf segments, were transferred to fresh PDA slants and maintained for further study. The fast growing fungi which inhibited the slow growing species, the were removed using sterile needle (Bills, 1996; Bills and Polishook, 1992). The endophytic fungi were identified morphologically using standard keys like conidia structure, conidial attachment and the fruit body structure (Onions, et al., 1981). The non sporulating sterile forms were given code numbers based on their colony color, texture, and mycelial structure (Rajagopal, 1999). The colonization frequencyof each endophyte was calculated as number of leaf segments that 
were colonized by a one or more isolate(s) from the total number of segments incubated $\times 100$ (Hata and Futai, 1995; Fisher and Petrini, 1987).

\section{$\mathrm{CF} \%=$ Colonization Frequency $/$ Percentage of Different groups}

Extraction and qualitative test for different chemical groups: All the endophytic fungi were cultured in $100 \mathrm{~mL}$ of Potato Dextrose broth using $250 \mathrm{~mL}$. Erlenmeyer flasks at $28^{\circ} \mathrm{C}$ in a rotary shaker $(150 \mathrm{rpm})$ separately and incubated for 3 weeks at $27 \pm 1^{\circ} \mathrm{C}$ in static condition. The crude extracts were prepared using organic solvents, namely ethyl acetate and diethyl ether. The mycelium was crushed along with solvents. Equal volume of the solvents was added and after extraction the mycelium along with solvents was centrifuged at $150 \mathrm{rpm}$ for 10 minutes and then the supernatant was used to test various chemical compounds. Different qualitative tests were conducted to detect alkaloids, flavonoids, diterpenoids and phenols present in the crude extracts of endophytic fungi of hydrophytes (Tiwari Prashant et al., 2011). The same extracts were used for antibacterial study.

Test for alkaloids: About $2 \mathrm{~mL}$. of the endophytic fungal extracts were dissolved individually in dilute hydrochloric acid and filtered. Dragendroff's Test- The filtrates were treated with Dragendroff's reagent (solution of Potassium Bismuth Iodide). Formation of red precipitate indicates the presence of alkaloids. Wagner's Test- Filtrates were treated with Wagner's reagent (Iodine in Potassium Iodide). Formation of brown/reddish precipitate indicates the presence of alkaloids.

Test for flavonoids: Each of the endophytic fungal extracts were tested for flavonoids individually. Alkaline Reagent Test: Individual endophytic fungal extracts were treated with few drops of sodium hydroxide solution. Formation of intense yellow colour and subsequent decolourization after adding dilute acid indicates the presence of Flavonoids. Lead Acetate Test: Endophytic fungal extracts were treated with few drops of lead acetate solution. Presence of flavonoids is indicated by yellow color precipitation.

Test for diterpenoids: Copper Acetate Test: Each of the endophytic fungal extracts were dissolved in water and and then treated with few drops of copper acetate solution, formation of emerald green colour indicates the presence of diterpene.

Test for phenol: Endophytic fungal extracts were treated with few drops of ferric chloride solution, formation of bluish black color indicates the presence of phenol.

In- vitro antibacterial activity: The bacterial species used for the antibacterial study included gram positive Streptococcus mutans (5\% Sheep Blood Agar), Bacillus subtilis (Standard -Nutrient Agar and Broth) and Staphylococcus aureus (Nutrient Agar and Mannitol salt Agar) and gram negative Escherichia coli (Nutrient/ CLED Agar), Klebsiella pneumoniae (MacConkey Agar / CLED Agar) and Salmonella typhi (Nutrient Agar / XLD Agar) bacteria. The bacterial cultures for study purpose were procured from VISTAS obtained from MTCC (Microbial Type Culture Collection) Chandigarh, India.
Disc diffusion method: The ethyl acetate and diethyl ether extracts prepared from four dominant endophytic fungi, $A$. alternata, $C$. incomptum, Phomopsis sp. and Sterile form I were tested against both gram positive and negative bacteria using a disc diffusion method (Yadav et al., 2010). About $25 \mu \mathrm{L}$ of each extract was added on to a sterile disc ( $\operatorname{size} 5 \mathrm{~mm}$ ) separately and allowed to dry for $10 \mathrm{~min}$. The disc containing different endophytic fungal extracts were placed on the respective medium with pathogens. The experiments were carried out in triplicates. Chloramphenicol dissolved in DMSO was used as control. The plates were incubated at $28^{\circ} \mathrm{C}$ to $35^{\circ} \mathrm{C} \pm 1$ for $24-48 \mathrm{hrs}$. The diameter of inhibition zone around the disc was measured by using ruler (Pavithra et al., 2012; Pundir et al., 2010; Rios et al., 1988; Hammer et al., 1999 and Junior and Zanil, 2000).

\section{RESULTSAND DISCUSSION}

Endophytic fungal research on trees, shrubs and herbs has aroused the interest of many mycologists in temperate and tropical region. Mycologists worldwide described the tropics as a "black box" with regard to our knowledge on endophytic fungi. Only handful of plant species from tropics and temperate region have been extensively studied for the presence of endophytic fungi (Suryanarayanan, 2017; Petrini, 1986). Whereas native hydrophytes have hardly been studied in this regard (Rajagopal et al., 2018). Hence, in the present study the leaf tissue of the hydrophytic plant, Aponogeton natans, was screened to document the presence of endophytic fungi. This host plant was found to be inhabited prominently by hyphomycetous fungi followed by ascomycetous fungi. In all three hundred and fifty one isolates belonging to 15 different endophytic species were isolated. Of which 7 were represented by hyphomycetous fungi $(46.6 \%), 4$ by ascomycetous fungi $(26.6 \%), 3$ by coelomycetous fungi $(20.0 \%)$ and 1 was a sterile form (6.6\%) (Table 1). Out of 15 endophytic fungi reported only seven endophytic fungi showed appreciable colonization frequency which was above $5 \%$ (Table 1). This observation is in conformity with that of Petrini (1986) who reported that only one or few endophytic fungal taxa are found dominating in a single host plant. Members of Zygomycetes and Basidiomycetes were not documented in the presently examined material. Otherwise also their presence is reported to be low in endophyte studies (Suryanarayanan et al., 1998). Alternaria alternata, Aspergillus fumigatus, Bactrodesmium sp., Curvularia ovoidea, Cytospora sp., Chaetomium incomptum and Phomopsis sp. were found to be dominant endophytes during the present study (Table 1). Most of the endophytic fungi isolated presently are also known to exist as endophytes in different host plants (Pelaez et al., 1998; Petrini, 1991; Murali et al., 2006). Some of the endophytic fungal genera like Alternaria, Drechslera, Aspergillus, Fusarium, and Curvularia are quite common as epiphytes. These fungi are also reported to penetrate superficial layers of host epidermis and by doing so, they are reported to overcome the strong surface sterilization step and they usually appear in endophytic fungal culture plates (Suryanarayanan et al., 1998; Cabral et al., 1993). This is reported to be indicative of the fact that epiphytic fungi too resort to an endophytic mode of life to beat the competition among epiphytic fungi on the 
Table 1: Distribution and various chemical groups produced by endophytic fungi isolated from leaf of $A$. natans

\begin{tabular}{|c|c|c|c|c|c|c|}
\hline Name of the Endophyte & CF\% & $\%$ & Alkaloid & Flavonoid & Diterpenoid & Phenol \\
\hline Hyphomycetous Fungi & & & & & & \\
\hline Alternaria alternata & 19.0 & \multirow{7}{*}{46.6} & + & + & + & + \\
\hline Aspergillus fumigatus & 14.0 & & + & + & + & + \\
\hline Bactrodesmium sp. & $\frac{1.0}{7.0}$ & & + & + & - & + \\
\hline Curvularia ovoidea & 7.6 & & + & + & + & + \\
\hline Cytospora sp. & 10.0 & & + & + & - & - \\
\hline Drechslera hawaiiensis & 3.0 & & + & + & + & + \\
\hline Graphium sp. & 1.0 & & + & + & - & - \\
\hline Ascomycetous Fungi & & & & & & \\
\hline Chaetomium incomptum & 6.0 & \multirow{4}{*}{26.6} & + & + & + & + \\
\hline Chaetomium globosum & 1.1 & & + & + & + & + \\
\hline Emericella nidulans & 1.0 & & + & + & + & + \\
\hline Glomerella sp. & 2.0 & & + & + & + & + \\
\hline Coleomycetous Fungi & & & & & & \\
\hline Colletotrichum sp. & 2.1 & \multirow{3}{*}{20.0} & + & + & - & - \\
\hline Phomopsis sp. & 5.0 & & + & + & + & + \\
\hline Phyllosticta sp. & 2.6 & & + & + & - & - \\
\hline \multicolumn{7}{|l|}{ Mycelia sterilia } \\
\hline Sterile form I & 1.0 & 6.6 & + & + & + & + \\
\hline $\begin{array}{l}\text { Total number of } \begin{array}{c}\text { Endophytes } \\
\text { and Compounds produced }\end{array} \\
\text { and }\end{array}$ & 15 & & 15 & 15 & 10 & 11 \\
\hline
\end{tabular}

surface of the leaf for survival, food and to escape from harsh environmental conditions (Rajagopal, 1999). Further, Aspergillus, Alternaria, Curvularia, Phomopsis, Pestalotiopsis, Chaetomium, Phyllosticta and Xylaria are well known multi-host endophytic fungi because of their wide distribution in plants of different ecosystems (Pandey et al., 2003; Sudhakara Reddy et al., 2016). Such a broad distribution of some endophytic fungi crossing host taxonomic and geographic restrictions has not been fully explained in literature.

The plant secondary metabolites as resistance-modifying agents play an important role in mitigating the spread of bacterial resistance (Othman et al., 2019). Natural compounds particularly from plant-associated microbes requires lot of efforts on the part of mycologists for exploration (Gunatilaka 2006). Several investigations has amply emphasized about the capacity of endophytic fungi to produce various chemical groups having different structural and functional properties (Zhang et al., 2012). Endophytic fungi from different plants are reported to be an important source of aldehydes, alkaloids, diterpenes, sesquiterpenes, terpenoids, xanthones, tannins, steroids, etc. (Ting et al., 2014; Souza et al., 2011). In the extracts of all the 15 endophytic fungi alkaloids and flavonoids were found to be present while Diterpenoids were documented onl;y in 10 endophytic fungi. Eleven endophytes were found to produce phenols (Table 1). All the ascomycetous fungi isolated presently produced all the four chemical groups tested (Table 1). Elena Martinez et al., (2016) stated that the endophytic fungi belonging to phylum Ascomycota is responsible for the production of several metabolites in culture in most of the studies. Once again in this study it was proved that Ascomycetous and Coleomycetous group of endophytic fungi were promising groups to produce diverse group of chemical compounds which are useful in medical, pharmaceutical and agricultural industry.

The most of endophytic fungal studies published in the recent past have shown the ability of endophytic fungi to produce antimicrobial compounds. In the current investigation an indepth study of Alternaria alternata, Chaetomium incomptum, Phomopsis sp. and sterile form I extracts were undertaken for antibacterial investigations. These fungi were selected for antibacterial investigations based on their colonization frequency and chemical compounds produced. For the extraction of metabolites from the fungal extracts, ethyl acetate (polar) and diethyl ether (non-polar) were used primarily because both the solvents have low toxicity, high volatility and these are commonly used as organic solvents in several studies. Presently the antibacterial activity was carried out using disc diffusion and agar well diffusion methods since both these methods are widely used in antibacterial studies to check the bioactivity of endophytic fungal metabolites (Verma et al., 2009; Buatong et al., 2011; Cui et al., 2011). The investigations were carried out employing Staphylococcus aureus, Streptococcus mutans, Bacillus subtilis belonging to gram positive group and Salmonella typhi, Escherichia coli and Klebsiella pneumoniae belonging to gram negative group of bacteria. In the disc diffusion method the ethyl acetate extract of $C$. incomptum showed mild activity against $S$. aureus $(22.4 \mathrm{~mm})$ and significant activity against $B$. subtilis $(23 \mathrm{~mm})$ (Fig. 1) while the ethyl acetate extract of Phomopsis sp. (22.6 mm) and $A$. alternata $(22.7 \mathrm{~mm})$ showed mild activity against $B$. subtilis (Fig. 1). As compared ethyl acetate extract of Phomopsis sp. showed significant activity against E. coli (20.1 mm) and K. pneumoniae (20.4 mm) (Fig. 2). In diethyl ether extract Phomopsis sp. did not show any significant activity against test gram positive bacteria and none of the other extracts also showed any activity against gram negative bacteria (Fig. 3). The diethyl ether extract of $C$. incomptum showed good activity against $E$. coli $(18.2 \mathrm{~mm})$ while in comparison Phomopsis sp. extract showed mild activity against $E$. coli $(17.8 \mathrm{~mm})$ and significant activity against $K$. pneumoniae $(18.9 \mathrm{~mm})$. Growth of none of the gram positive or gram negative bacteria was inhibited by the diethyl ether extracts of sterile form I (Fig. 4). The results of the

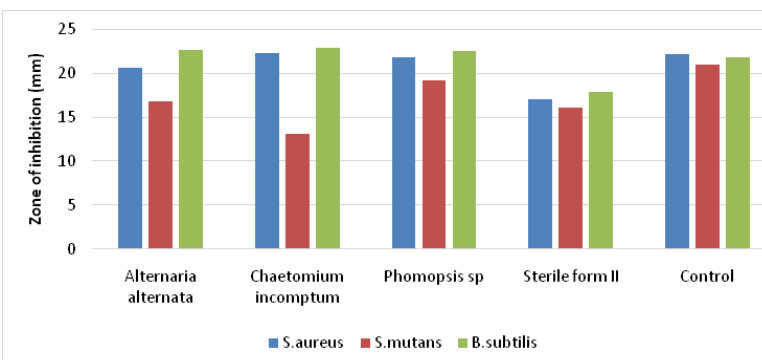

Fig. 1: In-vitro anti-bacterial activity of crude extracts from endophytic fungi using Ethyl acetate by disc diffusion method against gram positive bacteria.

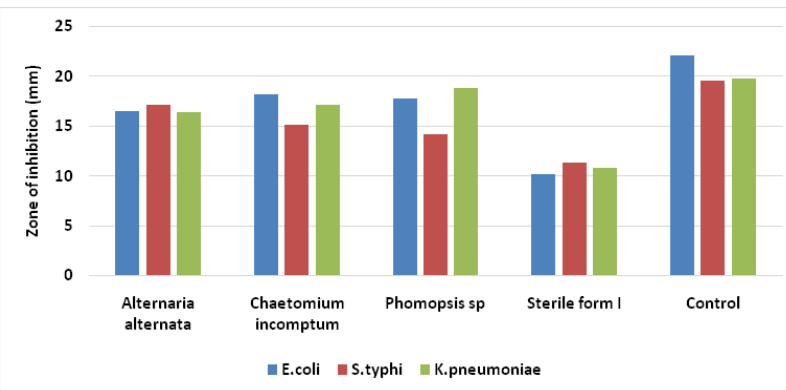

Fig. 2: In-vitro antibacterial activity of crude extracts from endophytic fungi using Ethyl acetate by disc diffusion method against gram negative bacteria. 


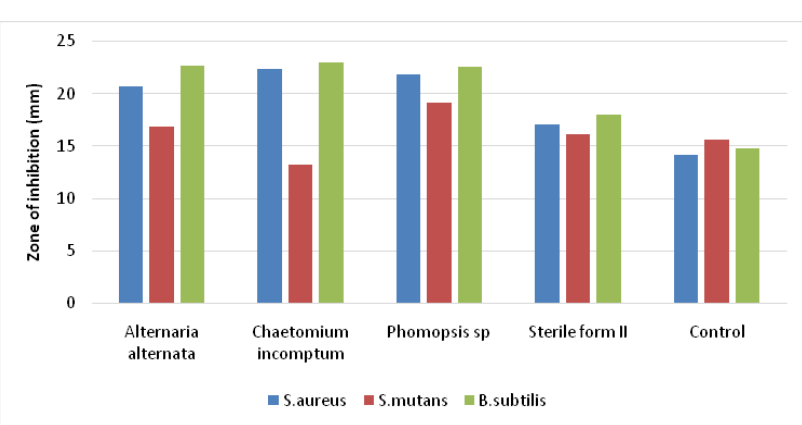

Fig. 3: In-vitro anti-bacterial activity of crude extracts from endophytic fungi using Diethyl ether by disc diffusion method against gram positive bacteria

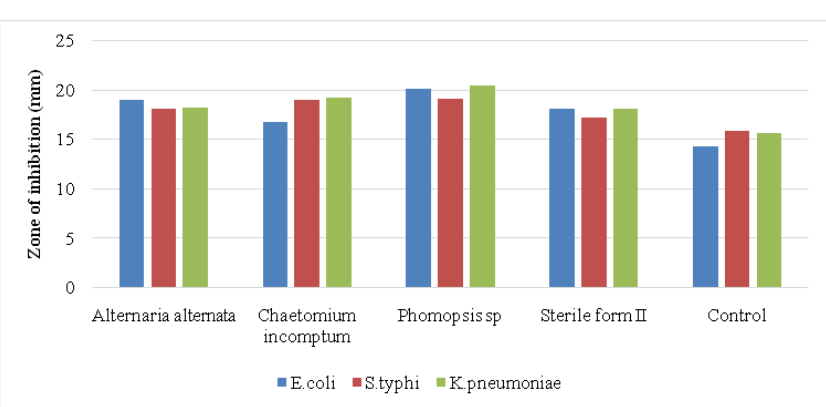

Fig. 4: In-vitro anti-bacterial activity of crude extracts from endophytic fungi using Diethyl ether by disc diffusion method against gram negative bacteria

antibacterial studies are in conformity with earlier such studies. Alvin et al. (2016) made similar observations when the ethyl acetate extract of Phomopsis sp. was tested against $S$. aureus and E. coli. Tonial et al., (2016) observed that ethyl acetate extract of A. alternata isolated from Schinus cerebinthifolius inhibited the growth of $S$. aureus and $P$. aeruginosa. Ethyl acetate extract of endophytic fungus Phomopsis sp. isolated from Avicennia officinalis and Avicennia alba has been reported to inhibit the growth of bacteria (Buatong et al., 2011). Palaez et al., (1998) reported wide differences among endophytic fungi in their ability to produce metabolites with antimicrobial activity. In the present investigation also it was found that endophytic fungi isolated from same environment showed varying degrees of in-vitro antimicrobial activities. Use of different solvents also matters a lot and plays a very important role in the extractions of compounds.

\section{CONCLUSION}

The hydrophytic plant Aponogeton natanshosts diverse classes of endophytic fungi which showed the presence of various bioactive compounds. The endophytic fungal study on $A$. natans showed that the leaf inhabiting endophytic fungi produced various chemical compounds and showed antibacterial activity against gram positive and gram negative pathogens. Hence, the hydrophytes might be a reservoir of endophytes that could produce various novel bioactive compounds which could be exploited for drug development.

\section{ACKNOWLEDGMENTS}

We sincerely thank the Vels Institute of Science Technology and Advanced Studies Management for their support towards the successful completion of the research work.

\section{REFERENCES}

Alva, P., McKenzie, E.H.C., Pointing, S.B., Muralla, R. and Hyde, K.D. 2002. Do sea grasses harbor endophytes? Fungal Diversity Res Series 7: 167178.

Alvin, A., Kalaitzis, J.A., Sasia, B. and Neilan, B.A. Combined genetic and bioactivity-based prioritization leads to the isolation of an endophytederived antimycobacterial. 2016.J. Appl. Microbiol. doi.org/10.1111/jam.13062.

Bills, G.F. and Polishook, J.D.1992. Recovery of endophytic fungi from Chamaecyparis thyoides. Sydowia 44: 112.

Buatong, J., Phongpaichit, S., Rukachaisirikul, V. and Sakayaroj. 2011. Antimicrobial activity of crude extracts from mangrove fungal endophytes. World $J$. Microbiol. Biotechnol. 27 (12): 3005-3008.

Cabral, D., Stone, J.K. and Carroll, G.C. 1993. The internal mycoflora of Juncus spp. microscopic and cultural observations of infection patterns. Mycol. Res. 97: 367-376.

Cui, J.L., Guo, S.X. and Xiao, P.G. 2011. Antitumor and antimicrobial activities of endophytic fungi from medicinal parts of Aquilaria sinensis. J. Zhejiang Univ Sci.B12 (5): 385-392.

Dobranic, J.K., Johnson, J.A., and Alikhan, Q.R. 1995. Isolation of endophytic fungi from eastern larch (Larix laricina) leaves from New Brunswick, Canada. Canadian Journal of Microbiology 41: 194-198.

Elena Martinez - Klimova, Karol Rodríguez Peña and Sergio Sánchez. 2016. Endophytes as sources of antibiotics. Biochemical Pharmacology134: 1-17.

Fisher, P.J. and Petrini, O. 1987. Location of fungal endophytes in tissues of Suaeda fruticosa: A preliminary study. Trans.Br.Mycol.Soc. 89: 246-249.

Frohlich, J., Hyde, K.D. and Petrini, O. 2000. Endophytic fungi associated with palms. Mycol Res.104: 12021212 .

Gonthier, P., Gennaro, M. and Nicolotti, G. 2006. Effects of water stress on the endophytic mycota of Quercus robur. Fungal Diversity 21: 69-80.

Gunatilaka, A. A. 2006. Natural products from plantassociated microorganisms: distribution, structural diversity, bioactivity, and implications of their occurrence. J. Nat. Prod. 69(3):509-526.

Hammer, K.A., Carson, C.F. and Riley, T.V. 1999. Antimicrobial activity of essential oils and other plant extracts. J. Appl. Microbiol. 86: 985-990.

Hata, K. and Futai, K. 1995. Endophytic fungi associated with 
healthy pine needles and needles infested by the pine needle gall midge. Thecodiplosis japonensis. Can. J. Bot.73: 384-390.

Jamith Basha, W. 2016. Distribution of Endophytic Fungi in Medicinally Important Hydrophytes and their Bioactivity. Ph.D. Thesis, Vels University, Chennai.

Junior, A. and Zanil, C. 2000. Biological screening of Brazilian medicinal plants. Braz. J. Sci. 95: 367-373.

Kumar, Seerangan and Muthukumar, Thangavelu. 2014. Arbuscular Mycorrhizal and Dark Septate Endophyte Fungal Associations in South Indian Aquatic and Wetland Macrophytes. $J$.Botany. https://doi.org/10.1155/2014/173125.

Li, W.C., Guo, S.Y. and Guo, L.D. 2007. Endophytic fungi associated with lichen Physcia stellaris using different surface sterilization methods. J. Fungl. Res. 5: 202-206.

Murali, T.S., Suryanarayanan, T.S. and Geeta, R. 2006. Endophytic Phomopsis species: host range and implications for diversity estimates. Can J. Microbiol. 52: 673-680.

Onions, A.H.S., Allosopp, D., and Eggins, H.O.W. 1981. Smith's Introduction to Industrial Mycology. $7^{\text {th }}$ Edition. Edward Arnold, London. pp.168-209.

Oses, R., Valenzuela, S., Freer, J., Sanfuentes, E. and Rodriguez, J. 2008. Fungal endophytes in xylem of healthy Chilean trees and their possible role in early wood decay. Fungal Divers. 33: 77-86.

Othman, L., Sleiman, A. and Abdel-Massih, R.M. 2019. Antimicrobial Activity of Polyphenols and Alkaloids in Middle Eastern Plants. Frontiers in microbiology 10:911.

Pelaez, F., Collado, J., Arenal, F., Cabello, A., Diez Matas, M.T., Garcia, J.B., Gonzalez Delval, A., Gonzalez, V., Gorrochattegui, J., Hernandez, P., Martin, I., Platas, G. and Vicente, F. 1998. Endophytic fungi from plants living on gypsum soils as a source of secondary metabolites with antimicrobial activity. MycolRes.102: 755-761.

Pandy, A.K., Reddy, M.S. and Suryanarayanan, T.S. 2003. ITS-RFLP and ITS sequence analysis of a foliar endophytic Phyllosticta from different tropical trees. Mycol Res. 107: 439-444.

Pavithra, N., Sathish, L. and Ananda, K. 2012. Antimicrobial and Enzyme activity of endophytic fungi isolated from Tulsi. J. Pharma BioMed. Sci. 16(12):1-6

Petrini, O. 1986. Taxonomy of endophytic fungi of aerial plant tissues. In:, Microbiology of the phyllosphere (Eds.: Fokkema, N.J. and van den Huevel, J.). Cambridge, UK: Cambridge University Press, 175187

Petrini, O. 1991. Fungal endophytes of tree leaves. In: Microbial ecology of the leaves (Eds.: Andrews, J.
H. and Hirano, S. S.), pp 179-197.

Pundir, Ram Kumar, Jain, Pranay and Sharma Chetan. 2010. Antimicrobial Activity of Ethanolic Extracts of Syzygium aromaticum and Allium sativum against Food Associated Bacteria and Fungi. Ethnobotanical Leaflets 14: 344-60.

Rajagopal, K., Meenashree, B., Binika, D., Joshila, D., Tulsi, P.S., Arulmathi, R., Kathiravan, G. and Tuwar, A. 2018. Mycodiversity and biotechnological potential of endophytic fungi isolated from hydrophytes. Current Research in Environmental \& Applied Mycology8(2): 172-182. doi 10.5943/cream/8/2/2.

Rajagopal, K. 1999. Biology and ecology of endophytic fungi from tropical trees with special reference to Neem (Azadirachta indica A. Juss) Ph.D. thesis, University of Madras, Chennai.

Rios, J.L., Recio, M.C. and Villar, A. 1988. Screening methods for natural products with antimicrobial activity: a review of the literature. $J$. Ethnopharmacol.23: 127-149.

Rungjindamai, N., Pinruan, U., Choeyklin, R., Hattori, T. and Jones, E.B.G. 2008. Molecular characterization of Basidiomycetous endophytes isolated from leaves, rachis and petioles of the oil palm, Elaeis guineensis, Thailand. Fungal Divers. 33: 139-161.

Souza, J.J.D., Vieira, I.J.C., Rodrigues-Filho, E. and BrazFilho, R. 2011. Terpenoids from endophytic fungi. Molecules16(12): 10604-10618.

Sudhakara Reddy, M., Murali, T.S., Suryanarayanan, T.S., Govinda Rajulu, M.B. and Thirunavukkarasu, N. 2016. Pestalotiopsis species occur as generalist endophytes in trees of Western Ghats forests of South India. Fungal Ecol. 24: 70-75.

Suryanarayanan, T.S., Kumaresan, V. and Johnson, J.A.1998. Foliar Fungal endophytes from two species of the mangrove Rhizophora. Canadian J. Microbiol. 44: 1003-1006.

Suryanarayanan, T.S. 2017. Fungal Endophytes: An Eclectic Review. Kavaka 48 (1):1-9.

Taylor, J.E., Hyde, K.D. and Jones, E.B.G. 1999. Endophytic fungi associated with the temperature palm Trachycarpus fortune within and outside its natural geographic Range. New Phytol.142: 335-346.

Ting Lin, Wing, G., Wenjun, S., Dequan, Z., Rong Ding, Xin, J., Dan, Z., Xiaoxuan, L., Shuiyun, Y. and Haifeng, C. 2014. Myrotheciumones: Bicyclic cytotoxic lactones isolated from an endophytic fungi of Ajuga decumbens. Biorganic \& Med. Chem. Letters 24 (11): 2504-2507.

Tiwari, Prashant Kumar, Bimlesh Kaur, M., Kaur G. and Kaur H. 2011. Phytochemical screening and Extraction: A Review. Internationale Pharmaceutica Sciencia.1: 98-106. 
Tonial, F., Maia, B.H., Gomes-Figureueiredo, J.A., Sobottka, A.M., Bertol, C.D. and Nepel, A. 2016. Influence of culturing conditions on bioprospecting and the antimicrobial potential of endophytic fungi from Schinus terebinthfolius. Curr. Microbiol.72 (2): 173-183.

Vellingiri Manon, Mani, Soundari, A.P.G., Karthiyaini, D., and Preethi, K. 2015. Bioprospecting of endophytic fungi and their metabolites from medicinal tree Aegle marmelos in Western Ghats, India. Mycobiology 43 (3): 303-310.

Verma, V.C., Gond, S.K., Kumar, A., Mishra, A., Kharwar, R.N. and Gange, A.C. 2009. Endophytic actinomycetes from Azadirachta indica A. Juss: isolation, diversity and anti-microbial activity. MicrobialEcol. 57 (4) 749-756.
Yadav, R., Nagendra, S., Chauhan Amit, Chouhan, S., Soni, V.K. and Omray, L. 2010. Antimicrobial screening of various extracts of Aphanmixis polystachya stems bark. International Journal of Advances in Pharmaceutical Sciences 1: 147-50.

You, Y.H., Park, J.M., Park, J.H. and Kim, J.G. 2016. Endophyte distribution and comparative analysis of diversity in wetlands showing contrasting geomorphic conditions. Symbiosis 69(1):21-36.

Zhang, H.H., Tang, M., Chen, H. and Wang, Y.J. 2012. Effects of a dark-septate endophytic isolate LBF-2 on the medicinal plant Lycium barbarum L. J. Microbiol. 50:91-96. 